\title{
FEDERALISMO Y DEMOCRACIA CONSOCIACIONAL EN LA POLÍTICA BELGA
}

\author{
CARLOS DE CUETO NOGUERAS \\ Profesor Titular de Ciencia Política y de la Administración \\ Universidad de Granada
}

\author{
SUMARIO \\ I. Introducción: el federalismo belga como \\ caso desviado. \\ II. La naturaleza centrifuga de disociación y \\ de superposición del esquema federal. \\ III. Gradualismo y asimetría federal belga. \\ IV. Federalismo consociacional protector de \\ las minorías. \\ V. Bélgica: ¿un federalismo de confronta- \\ ción a la deriva?
}

\section{INTRODUCCIÓN: EL FEDERALISMO BELGA COMO CASO DESVIADO}

Desde una estricta perspectiva de Política Comparada, Bélgica constituye, en cuanto a la organización territorial del poder político, un apasionante estudio de caso para el comparativista por su carácter desviado, ya que presenta ciertas características que lo distinguen de otras experiencias federales. Pero al mismo tiempo, del análisis del federalismo sui generis belga, como ya calificara el ex primer ministro Jean-Luc Dehaene al anunciar la reforma de Estado de 1993 en la conferencia de prensa de 17 de febrero, uno debe ser cauteloso pues la excepcionalidad del caso concreto limita el alcance de las enseñanzas que se pueden derivar de él. Este esquema federal hipercomplejo, asimétrico, en evolución constante, centrífugo de disociación, de superposición, bipolar y consociacional, orquestado en Bélgica, reflejo de la ambigüedad constructiva propia de la mentalidad política belga ${ }^{1}$, ha sido la

1 J. BEAUFAYS, "Les attitudes sécessionnistes en Belgique. Un séparatisme par inertie ? ", en Ch. BIDÉGARAY, Europe Occidentale, Le Mirage Séparatiste, Economica, París, 1997, págs. 234.

UNED. Teoria y Realidad Constitucional, núm. 24, 2009, pp. 545-563. 
fórmula o respuesta política-institucional más adecuada, para la elite política de este país, de cara a responder mejor a las necesidades de los ciudadanos, y a la heterogeneidad cultural, religiosa, ideológica y lingüística de la sociedad belga. El desarrollo institucional belga se ha constituido en la manifestación legal, a través de las instituciones del Estado, de una relación equilibrada entre el poder del nivel central de gobierno y la autonomía de las unidades constitutivas para que el Estado pudiera englobar varias naciones asumiendo el principio de subsidiariedad el papel de hilo conductor del proceso - todo lo que pueda ser resuelto a un nivel político inferior no debe ser transferido a un nivel de gobierno más elevado-. El federalismo belga ha buscado responder a las tensiones etnolingüísticas y gestionar el conflicto latente y manifiesto entre las comunidades lingüísticas existentes ${ }^{2}$.

\section{LA NATURALEZA CENTRÍFUGA DE DISOCIACIÓN Y DE SUPERPOSICIÓN DEL ESQUEMA FEDERAL}

A diferencia de Suiza, ejemplo paradigmático de federalismo de asociación donde las entidades soberanas originarias decidieron constituir voluntariamente una alianza confederal para convertirse posteriormente en Estado federal ( $E$ diversitate unitas), Bélgica es un ejemplo claro, junto a Austria, de un proceso inverso denominado centrífugo de disociación. El federalismo belga fue el resultado de las reivindicaciones de determinados grupos sociales, culturales y políticos internos a favor de la autonomía en el seno de un Estado unitario. A raíz de estas demandas, en Bélgica se inicia un proceso de federalización de un Estado unitario preexistente y el poder político se reparte entre el poder federal y las entidades federadas - comunidades y regiones- disponiendo cada nivel de gobierno de instituciones políticas propias, y de un paquete de competencias exclusivas que le han sido asignadas para ser ejercidas dentro de su territorio ${ }^{3}$.

A pesar del estéril debate mantenido sobre si ha existido alguna vez en su historia contemporánea una nación belga, lo cierto es que han sido los grupos lingüísticos francófono y neerlandés los que han forzado la federalización del Estado belga. Ya por el año 1912, el líder socialista Jules Destrée escribió una carta al rey donde afirmaba que "en Bélgica había valones y flamencos, pero no belgas». El Estado unitario y centralizado belga, proclamado por la Constitución del 7 de febrero de 1831, y organizado sobre la base de la doctrina del triple círculo —Estado, provincia y comuna - se transformaría progresivamente en un esquema federal. El amplio consenso interno que siguió a la proclamación oficial de independencia del 4 de octubre de 1830, entendida como

2 T.J. MAARTEN, "Leveled domestic politics. Comparing institutional reform and ethnonational conflicts in Canada and Belgium (1960-198)", Res Publica, Vol. XLIII, n. ${ }^{\circ}$ 1, 2001, pág. 38.

3 D. J. ELAZAR, Exploring Federalism, The University of Alabama Press, Tuscaloosa, 1987. 
una reacción nacionalista contra el poder extranjero ${ }^{4}$, empieza poco a poco a resquebrajarse por las emergentes líneas de división —cleavages- filosóficasreligiosas, lingüísticas, políticas y económicas. La segmentación o pilarización de la sociedad - verzuiling - se impuso al consenso inicial. La oposición entre los defensores de una sociedad basada en la Iglesia y los partidarios de una sociedad laica constituyó el primer elemento de conflicto interior que marca la división de la sociedad belga en la segunda mitad del siglo xIx y cuya consecuencia más clara fue el conflicto escolar entre los defensores de la enseñanza libre y oficial a raíz de las subvenciones públicas a los colegios cristianos 5 . Sin embargo, fueron las fricciones lingüísticas y socio-económicas las que promoverían definitivamente la federalización del Estado belga.

El emergente Estado belga de 1830 estaba dominado, por aquel entonces, por una élite francófona que no reconoció salvo muy lentamente la realidad flamenca. De hecho, la lengua oficial del Estado tanto para la enseñanza como para el mundo de los negocios, de la justicia y de la propia administración era el francés en exclusiva, como determinaba el decreto gubernamental provisional del 16 de noviembre de 1831. Hubo que esperar hasta el tercer cuarto del siglo XIX, tras las presiones y revueltas del movimiento flamenco a favor de los derechos lingüísticos individuales, formado básicamente por grupos de intelectuales y asociaciones culturales, para ver cómo fueron aprobadas las primeras leyes de reforma lingüística dirigidas a permitir en las provincias flamencas el uso del neerlandés para los procesos penales (ley de 1873), para la administración del Estado (ley de 1878), para la educación secundaria (ley de 1883) y para la promulgación y publicación de los textos legales en el Moniteur (ley de 1898) ${ }^{6}$. Para finales de siglo se había reconocido al neerlandés como lengua oficial en materia de justicia, administración y enseñanza secundaria y superior. Posteriormente, gracias a la extensión del cuerpo electoral por las reformas constitucionales de 1893 y 1921, y a la introducción del sistema de escrutinio proporcional para las elecciones parlamentarias en 1899, la creciente predominancia poblacional flamenca se trasladó por primera vez a la arena política. Por ello, tras la Primera Guerra Mundial un segundo conjunto de leyes lingüísticas fueron aprobadas, como la de 1921 y 1932, que sentaban las bases del principio de territorialidad lingüística que no se completaría hasta años después. A partir de la segunda mitad del siglo xx, cuando la cuestión lingüística se convierte en una cuestión política de primer orden y después de que el movimiento valón se opusiera al bilingüismo, los consolidados movimientos nacionalistas flamencos, unificados en torno al partido Volksunie creado en 1954, plantean la exigencia

4 En estos términos se expresa, J. Logie, 1830: De la Réginionalization à l'Indépendence, Gemgloux : Duculot, 1980.

5 D. L. SEILER, "Un système consociatif exemplaire: la Belgique", Revue Internationale de Politique Comparée, Vol. 4, n. ${ }^{\circ}$ 3, 1997, pág. 617.

6 A.B. MURPHY, "The Regional Dynamics of Language Differentiation in Belgium: A Study in Cultural-Political Geography", University of Chicago, Geography Research Paper N. 227 , Chicago, 1988, págs. 92-95. 
inmediata de completar el unilingüismo regional ${ }^{7}$. Como resultado final de esta labor legislativa lingüística quedó fijada definitivamente por la ley de 31 de octubre de 1962 la frontera lingüística/cultural germano-romana que dividía al país en la zona del norte de habla neerlandesa y la zona del sur de habla francesa. Esta ley establecía la obligatoriedad de utilizar la lengua oficial de las regiones unilingües ante la administración, la justicia, la enseñanza y en las relaciones laborales. Esta división o frontera lingüística devino en una frontera política-administrativa que dividía a Bélgica en cuatro regiones lingüísticas ${ }^{8}$ : tres de ellas unilingües - la región de habla neerlandesa, la región de habla francesa, la región de habla alemana- y una bilingüe, la región de Bruselas-capital donde el francés y el neerlandés coexistirían en pie de igualdad?. Una vez con-

7 «El gran éxito del partido populista y etnocéntrico sucesor del Volksunie, el Vlaams Blok, actualmente denominado Vlaams Belang, ha descansado en una retórica fácil de oposición a la inmigración, a la construcción europea, a los partidos tradicionales y a favor de un Flandes independiente. En su discurso identitario busca la utopía de una comunidad étnica homogénea que permita hacer coincidir al Estado con la nación", F. LEHNER y B. OMÁN, "Consociational Decisión-making and Party Government in Switzerland", en R.S. KATZ (Ed.), Party Government, European and American Experiences, Walter and Gruyter, Berlin, 1987, pág. 189.

8 La región de habla neerlandesa, Flandes, englobaría a unos 5,8 millones de habitantes - 51,81\% de la población belga - y abarcaría las provincias de Flandes Oriental, Flandes Occidental, Amberes, Limburgo y lo que hoy es Brabante flamenco. La región de habla francesa englobaría, por su parte, a unos 3,2 millones de habitantes - 31,95\% — abarcando las provincias de Namur, Hainaut, Luxemburgo, Brabante Valón y Lieja, salvo sus nueve comunas orientales que constituían la región de habla alemana, con una población de 68.000 habitantes — 0,68\%-. Este territorio fue resultado de la anexión a Bélgica, tras la Primer Guerra Mundial, de los cantones alemanes de Eupen, Malmédy, Saint-Vith y Moresnet. Y por último, se encontraba la región bilingüe de Bruselas-capital con una población de 950.000 habitantes — 9,56\% de la población belga total - englobando las 19 comunas del área metropolitana de la gran Bruselas.

9 Con objeto de proteger la situación de las minorías lingüísticas individuales surgidas a raíz de la ley de 1962, el de aquellas personas que hablasen una lengua distinta a la oficial de alguna de las tres regiones unilingües, se crearon las denominadas comunas o municipios a facilité. Se trata de una excepción al principio de territorialidad lingüística al permitir a sus habitantes el derecho a utilizar su propia lengua para los asuntos administrativos, judiciales y laborales, así como el derecho a recibir educación en su propia lengua, distinta a la oficial de la región en la cual se encuentra situada la comuna. Estas comunas se encuentran a lo largo de la frontera lingüística y en la periferia de la región de Bruselas-capital y cualquier modificación a dicha normativa, regulada en al artículo 129 de la constitución, exigiría ser aprobada por ley federal de mayoría especial. No obstante, a petición de los parlamentarios francófonos G. Clerfayt y A. De Decker en julio de 1997, la Asamblea del Consejo de Europa examinó y emitió un informe redactado por la suiza Dumeni Columberg y adoptado por la Comisión de Asuntos Jurídicos y Derechos Humanos el 3 de septiembre de 1998 sobre la situación de la población francófona que vive en ciertas comunas en la periferia de Bruselas. En dicho informe se recomienda al gobierno flamenco, no sólo cesar en sus intentos de reducir o dificultar las facilidades lingüísticas de dichas comunas a través de las circulares de los ministros Peeters (diciembre 1997), Martens (febrero 1998) y Van Den Brande (octubre 1997), así como las prácticas de asimilación lingüística forzosa. De igual modo, este informe recomendaba a Bélgica suscribir la Convención Marco del Consejo de Europa sobre la protección de las minorías nacionales e insinuaba que algunos francófonos de Bélgica no gozan de un estatus democrático, que las fronteras de Bruselas no fueron asignadas o determinadas de una forma democrática, o que los habitantes francófonos de la provincia flamenca de Brabante no tienen el derecho a usar su propia lengua. Para analizar estas conclusiones, pueden consultarse las obras de S. FIERS y M. DEWEERDT, "Belgian Politics 
seguido esta demarcación lingüística, regulada en el artículo 4 de la Constitución y que exigía una ley federal de mayoría especial para su modificación, el movimiento flamenco con extrema moderación vuelca toda su energía en impulsar el proceso federal del Estado belga como culminación de este reconocimiento de la particularidad, especificidad y autonomía flamenca.

Por otro lado, tras la Segunda Guerra Mundial, a raíz de una grave crisis económica e industrial que azota especialmente a Valonia, el poderoso movimiento sindicalista valón, de la mano de uno de sus principales líderes, André Renard, apuesta decididamente por la federalización del Estado belga como única solución para remediar el declive socio-económico imparable de Valonia que se plasmó en la oleada de huelgas de 1960/1. Esta apuesta por el régimen federal ya, en octubre de 1945, había sido respaldada por casi la unanimidad de los miembros del Congreso Nacional Valón. El proceso de federalización de las estructuras unitarias del poder político, que se habían mantenido intactas en Bélgica desde 1830, estaba listo para ser iniciado a mediados de los años sesenta cuando las dos comunidades básicas de la sociedad belga, francófona y neerlandesa, y más concretamente, Valonia y Flandes, coincidieron en la idoneidad de esta fórmula de organización territorial del poder político. Esta convergencia de intereses, culturales/lingüísticos por parte de los flamencos y económicos por parte de los valones, hizo que la geografía lingüística de Bélgica se convirtiera en la base o fundamento sobre el cual se construiría la nueva estructura política ${ }^{10}$.

Del lado valón, el poderoso movimiento sindical inspirado por un escenario de lucha de clases, defendía la federalización bajo una lógica regionalista/racionalista reclamando para su región el auto-gobierno socioeconómico necesario para su recuperación económica. En el lado flamenco, el movimiento nacionalista, exaltado por las memorias de sufrimiento y lucha durante la época de dominación francófona, se inscribía en una lógica nacionalista cultural, caracterizada por la defensa y reconocimiento de una herencia y autonomía cultural-lingüística de envergadura y por la representación de su región como auténtica nación ${ }^{11}$. Así, el federalismo de superposición del caso belga, de extraordinaria originalidad frente a las experiencias federales estrictamente territoriales, pasará a constituirse en una de las características diferenciadoras de este caso de estudio, aunque en la práctica se inscribe en la categoría de federalismo parcialmente personalizado toda vez que el campo de acción de las comunidades está definido territorialmente ${ }^{12}$.

in 1998", Res Publica, Vol. XLI, 1999, págs. 277-284 y de C. Franck y X. MABILLE, "La Belgique en 1998, Tensions et Incertitudes ", en A. GROSSNER, Les Pays d'Europe Occidentale, Documentation Française, Édition 1999, págs. 99-113

10 A. MURPHY, "Belgium's Regional Divergence: Along the Road to Federation", en G. SMITH (Ed.), Federalism: the Multiethnic Challenge, Longman, London, 1995, pág. 75.

11 A.P. FROGNIER, "The mixed nature of Belgian Cabinets: between mayority rule and consociationalism", European Journal of Political Research, 1988, vol. 16, págs. 203-205.

12 P. De BRUYCKER, M. LEROY, J. SOHIER, P. VANDERNACHT, P. VANDERNOOT, "Mécanismes institutionnels et droits individuels dand la protection des minorités de la Belgique fédérale", en N. LEVRAT, Minorités et organisation de l'Etat, Bruselas, Bruylant, 1998, pág. 193. 
Esta doble motivación federalizante, esta discrepancia en las concepciones de partida defendidas por ambos grupos, ha provocado que el proceso de federalización del Estado belga se haya llevado a cabo bajo el reconocimiento simultáneo de una doble naturaleza operativa, la comunitaria y la regional. Esta doble lógica organizacional ha provocado que dos tipos de instituciones o entidades federadas — comunidades y regiones - se superpongan ejerciendo sobre sus casi idénticas jurisdicciones territoriales competencias diferentes ${ }^{13}$. Si la lógica federalizante regional descansa en el principio de territorialidad (ius solis) y trata de atribuir a las entidades federadas el poder de actuar sobre un territorio concreto y preciso y sobre la totalidad de los individuos que habiten en dicho territorio independientemente de su carácter cultural, la lógica federalizante comunitaria descansa, por el contrario, sobre el principio de la personalidad (ius personae). Sobre la base de este principio de la personalidad las entidades federadas cuadran o encajan con las comunidades compuestas por las personas que comparten ciertos rasgos culturales, en este caso lingüísticos, y están habilitadas para intervenir en su favor. Pero esta doble lógica federalizadora ha llevado a una evolución asimétrica en las estructuras del lado flamenco y valón. Así, en el lado flamenco se ha impulsado el carácter comunitario-cultural del federalismo belga, como pudo evidenciarse cuando en 1980 las autoridades flamencas fusionaron las instituciones regionales y comunitarias, y por su parte, en el lado valón se ha primado y reforzado la dimensión regional-territorial ${ }^{14}$. Desde esta perspectiva hay que interpretar la transferencia de competencias propias de la Comunidad Francesa en favor de la Región de Valonia y de la Comisión Comunitaria Francesa de la región de Bruselas-capital, así como la progresiva transferencia de competencias de la Región de Valonia a la Comunidad Germanófona.

Bélgica ha sabido organizar sobre el mismo territorio una de las construcciones institucionales y esquemas federales más complejos y originales del mundo que permite expresarse a múltiples voluntades políticas, y que coexistan dos juegos de colectividades federadas con diferentes competencias e intereses.

\section{GRADUALISMO Y ASIMETRÍA FEDERAL BELGA}

Actualmente el artículo 1 de la Constitución establece que Bélgica es un Estado federal compuesto por comunidades y regiones. Esta realidad constituye el resultado de un proceso progresivo de federalización, no acabado, de

13 D. VAN DAM, "L'Identité des dirigeants en Flandre et en Wallonie ", Revue Internationale de Politique Comparée, Vol. 5, n. ${ }^{\circ}$ 1, 1998, pág. 203 ; D. REA (Ed.), Political Co-operation in Divided Societies. A series of papers relevant to the conflict in Northern Ireland, Gill and Macmillan, Dublin, 1999, pág. 209.

14 O. ASTEENS, "Comment la Belgique va-t-elle exister?", en N. BURGI, Franctures de l'Etat nation, Kimé, París, 1994, págs. 186-187; W. SWENDEN, M. BRANS y L. DE WINTER, "The Politics of Belgium: Institutions and Policy under Bipolar and Centrifugal Federalism", en Special Issue on the Politics of Belgium, West European Politics, noviembre 2006, vol. 29, n. 5, págs. 863-873. 
un Estado unitario y centralizado, cuyos pilares fundamentales se establecieron en la revisión constitucional de 1970 y se consolidaron con las cuatro sucesivas reformas de Estado de 1980, 1988, 1993 y 2001. Estos amplios y complejos acuerdos políticos de compromiso, como el de Saint-Michel de 1992, de visiones bien diferentes defendidas por las partes contendientes fueron posibles gracias a la responsabilidad de una serie de políticos inspirados por la voluntad de triunfar y alcanzar acuerdos por medio de concesiones recíprocas que permitieran crear estructuras autónomas que gestionaran mejores soluciones políticas a las problemáticas propias de cada comunidad/ región.

Las sucesivas reformas de Estado llevadas a cabo a partir de 1970, y a pesar de la falta de acuerdo inicial entre ambas comunidades sobre los límites, estatus y competencias de la región de Bruselas-capital, lo cual retrasó la puesta en marcha de la organización institucional regional, identificaron las nuevas entidades federadas sobre las que descansaría la nueva estructura federal del Estado belga. Así, junto a la división del territorio belga en las cuatro regiones lingüísticas anteriores, la Constitución inscribe el principio regional y comunitario en la organización del nuevo Estado y reconoce tres regiones -Flandes, Valonia y Bruselas-capital - y tres comunidades - Germanófona, Flamenca y Francófona - en Bélgica. Si a las regiones se les asignaba competencias exclusivas sobre asuntos socioeconómicos y materias "localizables" - medio ambiente, ordenamiento rural, agricultura, preservación de la naturaleza, economía, energía, empleo, planificación del territorio, comercio exterior, vivienda, transportes públicos, infraestructuras, política científica y supervisión de comunas y provincias-, por el contrario, a las comunidades, denominadas por aquel entonces culturales, se les otorgaron, junto a las competencias de educación, política cultural —bellas artes, bibliotecas, turismo, deportes, y medios audiovisuales - y uso de la lengua, exclusividad sobre las denominadas materias "personalizables" — política de salud, medicina preventiva, política familiar, juventud, hospitales, asistencia social a la tercera edad, integración de discapacitados, acogida de inmigrantes, etc. ${ }^{15}$. Una vez distribuidas las competencias entre las entidades federadas - regiones y comunidades-, se emprendió la conformación institucional de las mismas. Cada una contaría con un gobierno autónomo, y una asamblea responsable de adoptar decretos en el ámbito de sus competencias exclusivas. Con el paso del tiempo los miembros de estas asambleas autónomas serían elegidos de forma directa, salvo los casos concretos de la Comunidad

15 El nivel federal asumía dos tipos de competencias, por un lado, las no asignadas a los niveles federados subnacionales como finanzas, unión económica y monetaria, deuda pública, política fiscal, política monetaria, política de precios y de ingresos, protección del ahorro, empresas públicas, política exterior, defensa nacional, justicia, seguridad social, orden público, legislación civil, penal, comercial, etc., y por otro, ciertas excepciones a las asignadas a comunidades y regiones, como el uso de la lengua en la Comunidad Germanófona, en Bruselas-capital o en las comunas "a facilité". 
Francófona y Flamenca ${ }^{16}$, para reforzar la autonomía de los Consejos regionales y evitar las consecuencias perversas de la representación o mandato múltiple de los diputados federales, ya que inicialmente estos Consejos se nutrían de los parlamentarios del nivel federal. A pesar de que el doble mandato en sociedades plurales puede ser considerado como un elemento que facilita el proceso de acomodación de intereses en democracias consociacionales ${ }^{17}$, la apuesta por fortalecer la legitimidad democrática de estas entidades federadas se consideró más apremiante. Pero es probablemente la complejidad y el carácter asimétrico lo que mejor define a este esquema institucional subnacional.

Aunque existen ciertas características comunes compartidas por comunidades y regiones —el carácter unicameral, monista y fijo de las legislaturas de los Consejos comunitarios y regionales al no estar prevista la disolución anticipada, mandatos de cinco años frente a los cuatro del parlamento federal, el carácter constructivo de las mociones de censura contra los gobiernos autónomos, la responsabilidad individual de los miembros de estos ejecutivos autónomos ante sus asambleas frente a las investiduras colegiales, la estructura primus inter pares de los ejecutivos federados junto a un poder reglamentario colegial, etc. ${ }^{18}$. - son las especificidades propias de cada nivel de gobierno y de cada institución del mismo nivel político, cuya máxima expresión se visualiza en la región de Bruselas-capital, las que verdaderamente definen a este sistema federal. Estas especificidades son relativas al sistema de elección de los miembros de sus asambleas, al doble mandato de los miembros de los gobiernos autónomos y a las titularidades competenciales asumidas. La extensa autonomía organizacional y constituyente de las colectividades federadas hace que nos enfrentemos a un federalismo ostensiblemente asimétrico. Así, los 25 consejeros de la Asamblea comunitaria alemana, a diferencia de los consejeros no electos de las Comunidades Francófona y Flamenca, son elegidos de forma directa por los habitantes de esta región. Por su parte, cabe mencionar el doble mandato de los ministros del gobierno regional de Valonia, ya que algunos de ellos suelen ser, al mismo tiempo, miembros del ejecutivo de la Comunidad Francófona y éstos, a su vez, pueden y suelen ser miembros del gobierno regional de Bruselas-capital ${ }^{19}$. Y en

16 De los 124 miembros del Consejo de la Comunidad Flamenca, 118 serían los consejeros electos del Consejo regional de Flandes y los 6 restantes serían designados en el seno del grupo lingüístico neerlandés del Consejo de la Región de Bruselas-capital. Por su parte, los 94 miembros del Consejo de la Comunidad Francófona consistirían de los 75 consejeros electos del Consejo de la Región de Valonia junto a 19 diputados adicionales elegidos entre los miembros del grupo lingüístico francófono del Consejo regional de Bruselas-capital.

17 F. LEHNER Y B. OMÁN, op. cit., pág. 193.

18 Características todas ellas que configuran un sistema de parlamentarismo racionalizado, como se describe en la obra de P. LAUVAUX, Parlamentarisme rationalisé et stabilité du pouvoir exécutif. Quelques aspects de la réforme de l'État confrontés aux expériences étrangéres. Bruylant, Bruselas, 1988.

19 La fórmula que ha primado desde 1995 consistía en que de los cuatro miembros del gobierno de la Comunidad Francófona, dos lo fueran al mismo tiempo del gobierno valón, uno del 
lo relativo a las diferencias de competencias asumidas, es importante recordar que la Región de Valonia cuenta, por un lado, con menos competencias respecto al resto de regiones belgas, una vez que en 1994 la región valona cediera a la Comunidad Germanófona la competencia sobre monumentos y parajes, mientras por otro, cuenta con mayores competencias que el resto de las regiones belgas, pues ejerce ciertas competencias comunitarias que le han sido transferidas por la Comunidad Francófona a raíz de la reforma de Estado de 1993 como política de asistencia y atención social, ayuda a las personas, turismo, transporte escolar, formación profesional, infraestructuras deportivas, cuidado a discapacitados, etc ${ }^{20}$. Por tanto, esta transferencia de prerrogativas puramente comunitarias realizada por la Comunidad Francófona a favor, tanto de la Asamblea de la Región de Valonia como del grupo francófono de la Asamblea de la Región de Bruselas-capital _Cocof-, evidencia que esta Comunidad ejerce menos competencias que las otras dos comunidades del esquema federal belga. Sin embargo, esta asimetría competencial entre comunidades no es equiparable, ya que la Comunidad Germanófona, no sólo carece de cualquier autonomía constituyente y del nivel de autonomía fiscal que gozan las otras, sino que carece de la competencia comunitaria más importante sin lugar a dudas, el uso de la lengua en materia de enseñanza, aunque si lo ejerza en asuntos administrativos y sociales. El empleo del uso de la lengua en el ámbito escolar queda en manos de las autoridades federales. Y por último, para complicar más aún este mapa de titularidades competenciales de entidades federadas, hay que hacer referencia a la decisión tomada en 1980 por las autoridades neerlandesas, gracias a su autonomía constituyente, de fusionar las instituciones regionales y comunitarias flamencas en una sola institución: la Comunidad Flamenca -Vlaamse Gemeenschap_- Gracias a esta decisión, se erige un único poder, ésta vez el comunitario, en el campo flamenco dotado de una única asamblea y de un único gobierno autónomo, quien gestionará las materias o competencias regionales y comunitarias asignadas por las sucesivas reformas constitucionales ${ }^{21}$. De hecho, muchos autores hablan no tanto de fusión de entidades, sino de que la Comunidad Flamenca haya absorbido a la Región de Flandes para primar

gobierno de Bruselas-capital y otro que fuera estrictamente comunitario que asumiera el puesto de ministro-presidente.

20 Esta cesión de competencias comunitarias en favor de ambas instancias regionales no obedecía exclusivamente a la lógica federalizadora regional-territorial de los valones. Buscaba principalmente atenuar las graves dificultades financieras y presupuestarias de la Comunidad Francófona, manteniendo su control sobre las actividades consideradas más importantes para su jurisdicción: enseñanza, cultura y audiovisual.

21 Esta reforma tiene dos limitaciones importantes. Mientras la primera consiste en que los decretos sobre competencias regionales — trabajos públicos, economía, empleo, etc.— adoptados por el parlamento flamenco no afectan a Bruselas-capital, la segunda se refiere a que ni los parlamentarios del Consejo Flamenco que provengan del grupo lingüístico neerlandés del Consejo regional de Bruselas-capital ni los ministros del gobierno flamenco que provengan de la región de Bruselas, pueden participar ni en las deliberaciones, ni obviamente en las votaciones de las materias referidas a las competencias regionales. 
la dimensión comunitaria del federalismo belga en torno a las dos grandes comunidades lingüísticas existentes ${ }^{22}$.

Pero sin lugar a dudas la región de Bruselas-capital personifica la máxima expresión de esta complejidad y asimetría propias del federalismo belga. Que no fuera puesta en marcha hasta 1989 evidencia las enormes discrepancias que suscitaba por su carácter bilingüe, por su relevancia política comunitaria, nacional e internacional, por la imperiosa necesidad de encontrar mecanismos de protección de la minoría flamenca, por tratarse del único territorio que es compartido por la jurisdicción de la Comunidad Francófona y Flamenca, y por encontrarse en el centro de la confluencia de la doble lógica regional y comunitaria que da especificidad al federalismo belga. Las particularidades de este nivel de gobierno obligaron a poner en marcha un diseño institucional especialmente complejo y unas reglas específicas en el funcionamiento de esta región. Junto a los mecanismos consociacionales implementados para proteger a la minoría flamenca — los grupos lingüísticos del Consejo Regional, la paridad lingüística en la conformación del Colegio Regional, etc.- , que comentaremos más adelante, existen ciertas particularidades en el diseño institucional y en el funcionamiento de esta región que merecen ser resaltadas en este momento. A diferencia del resto de comunidades y regiones, cuyos consejos gozan de capacidad legislativa en forma de decretos para sus competencias asignadas en exclusiva, el poder legislativo del Consejo regional de Bruselas-capital se materializa en forma de ordenanzas. Esta diferencia terminológica implica que, a diferencia de los decretos regionales y comunitarios y de las leyes federales, las ordenanzas pueden ser objeto de revisión judicial. Su constitucionalidad puede ser controlada por los tribunales ordinarios, y en determinados casos por las jurisdicciones administrati$\operatorname{vas}^{23}$. Al mismo tiempo, al ser el único territorio del país que carece de nivel provincial, asume, a diferencia de las otras regiones, las competencias provinciales propias. Y por último, en el seno del Consejo regional de Bruselas se crearon tres comisiones: la Comisión Comunitaria Francesa ${ }^{24}$ (Cocof), que gracias a la delegación o transferencia de competencias hecha por la Comunidad Francófona le permite convertirse en una auténtica asamblea legislativa con poder reglamentario propio en su territorio para adoptar decretos sobre

22 J. BRASSINE, "L'irréversibilité de l'asymétrie des institutions ", Problèmes Politiques et Sociaux, n. ${ }^{\circ}$ 795, en J-C. BOYER, Belgique : l'Etat Fédéral, une étape?, diciembre de 1997, pág. 41.

23 La capacidad legislativa de Bruselas, como capital europea y, al mismo tiempo, como capital del Estado federal y capital tanto de la Comunidad Francófona como de la Comunidad Flamenca, hacía conveniente que el poder federal pudiera anular o suspender las ordenanzas regionales referidas a cuestiones de urbanismo, ordenación territorial, trabajos públicos o transportes cuando estimase que pusieran en peligro o perjudicase el papel internacional o la función de capital del Estado.

24 Esta Comisión estaría formada por la totalidad de los consejeros francófonos del Consejo regional de Bruselas-capital para tratar las cuestiones comunitarias referidas al territorio de Bruselas y su gobierno o colegio lo constituyen los dos ministros regionales francófonos, los dos secretarios de estado francófonos del gobierno regional y el ministro del gobierno de la Comunidad Francófona residente en Bruselas, el cual sólo tiene voz consultiva. 
materias relevantes de competencia comunitaria; la Comisión Comunitaria Flamenca (VGC) ${ }^{25}$; y la reunión conjunta de las dos anteriores, la Comisión Comunitaria Común (Cocom) ${ }^{26}$.

Una vez conformado todo el entramado institucional de las entidades federadas — comunidades y regiones - del federalismo de Bélgica, se perfilaron una serie de aspectos igualmente claves para culminar este proceso de federalización, de los cuales estimo que cuatro merecen una consideración especial. En primer lugar, se pone en funcionamiento un nuevo órgano jurisdiccional, la Corte de Arbitraje, encargado de dirimir los potenciales conflictos competenciales entre los distintos niveles de gobierno y asumir el control de la constitucionalidad de las leyes o decretos, aunque este poder se limite a verificar el respeto al reparto de competencias entre la federación, las comunidades y las regiones que consagra el texto constitucional tras las reformas de Estado aprobadas hasta la fecha.

En segundo lugar, se instaura todo un entramado de comités ministeriales, conferencias intergubernamentales, así como de procedimientos de consulta y acuerdos de cooperación dirigidos a poner las bases de una ambiciosa estructura de cooperación y concertación multinivel, vertical entre el Estado y las regiones y comunidades de una parte, y horizontal entre las regiones y comunidades de otra ${ }^{27}$. Los principios de complementariedad, interdependencia y mutua influencia en el ejercicio de sus poderes y competencias se han impuesto a los de separación y autonomía entre las autoridades constitutivas y la federación, de forma que el fraccionamiento del poder político, o mejor dicho el despojo de competencias del Estado central en favor de las entidades autónomas, no ha resultado en una compartimentación estanca e impermeable ${ }^{28}$. La naturaleza bipolar de la vida política belga exigía

25 Esta Comisión - VGC - está compuesta por los miembros del grupo lingüístico flamenco del Consejo regional de Bruselas-capital, mientras su colegio lo conforman los dos ministros flamencos del gobierno de Bruselas, el secretario de estado regional flamenco más el ministro flamenco residente en Bruselas del gobierno de la Comunidad Flamenca. A diferencia del Cocof, sus decisiones se toman en forma de reglamentos pues la Comunidad Flamenca no ha delegado a su favor ningún poder reglamentario sobre competencias comunitarias en dicho territorio. De esta forma, su tarea se limita a subvencionar y gestionar las instituciones culturales y sociales, impulsar actividades de investigación sobre el patrimonio arquitectónico, exposiciones, publicaciones y encuentros dirigidos a expandir la lengua y cultura neerlandesa en la capital del reino.

26 Estaría formada por todos los miembros del Consejo regional de Bruselas-capital, pero reunidos para tratar, en este caso, no cuestiones o competencias regionales, sino cuestiones bicomunitarias, o materias comunitarias comunes de los habitantes de Bruselas y sus actos o decisiones deben tomarse por mayoría de ambos grupos lingüísticos.

27 B. DE WITTE, "Regional autonomy, cultural Diversity and European integration: the experience of Spain and Belgium", en S. ORTINO, M ZAGAR Y V MASTNY (Ed), The Changing faces of Federalism, Institutional reconfiguration in Europe from East to West, Manchester University Press, Manchester, 2005, pág. 205.

28 Para evitar conflictos competenciales entre los distintos niveles de gobierno, la Constitución instauró dos principios básicos del federalismo belga. Por un lado, se establece un sistema de devolución de poderes basado en el principio de exclusividad competencial en un plano material y geográfico, lo que aseguraba la inexistencia de ingerencia alguna entre niveles. Y por otro, cabe resaltar el principio de no jerarquía o de igualdad jurídica entre las normas emanadas 
una estrecha colaboración entre los distintos niveles de gobierno en los procesos de toma de decisiones en el ámbito de sus propias competencias para garantizar una cierta unidad y coherencia en determinadas materias y evitar los posibles conflictos competenciales que pudieran plantearse entre ellos.

En tercer lugar, se revisa el sistema bicameral federal con objeto de garantizar una adecuada participación de las entidades federadas en el proceso de toma de decisiones a nivel federal a través de la cámara alta o Senado belga, que desde ese momento se le encargaría la representación de comunidades y regiones y el papel de guardián de la lealtad federal en caso de conflicto político de intereses entre los distintos parlamentos. Para ello el sistema bicameral a nivel federal sufrió un profunda reestructuración, pero en el sentido opuesto al esperado. Hasta aquel momento la Cámara de Representantes y el Senado gozaban de las mismas competencias por lo que existía una clara simetría legislativa federal. Pero con la reforma la Cámara de Representantes deviene en la asamblea política por excelencia. No sólo desde ese momento será la Cámara de Representantes la única competente tanto para aprobar el presupuesto como para fiscalizar y exigir o comprometer la responsabilidad política del gobierno federal (art. 101 y 174 de la constitución), sino que además juega un papel preponderante en la adopción de las leyes. Salvo en las revisiones constitucionales, en el asentimiento de los tratados internacionales, en las leyes lingüísticas y electorales, en los acuerdos de cooperación entre el Estado, las comunidades y las regiones y en las leyes relativas a la organización de la estructura y funcionamiento del Estado (art. 77), donde el Senado actúa de oficio y en pie de igualdad gozando de poder de veto absoluto, para el resto de las leyes la cámara alta actuará más bien como cámara de depuración o reflexión. Es la cámara baja quien tiene la última palabra en su aprobación final, y en todo caso, el Senado contará con plazos muy estrictos para examinarlas. A esta irrelevancia legislativa del Senado hay que añadir su híbrida composición ${ }^{29}$, fiel reflejo de la estructura bipolar del Estado belga, centrado en las dos principales comunidades despreciando el factor regional de su ecuación representativa. Estas características del Senado han provocado un bicameralismo desequilibrado en favor de la cámara baja federal, un bicameralismo simbólico donde el Senado sólo ostenta un papel

de los distintos niveles de gobierno, como decretos comunitarios, decretos regionales y leyes federales.

29 El Senado belga está compuesto por cuatro tipos de miembros. El primer grupo de 40 senadores lo conforman los senadores electos, elegidos de forma directa por los ciudadanos belgas. Para su elección el cuerpo electoral se divide en dos colegios electorales, al igual que ocurre para las elecciones al Parlamento Europeo. El colegio francófono elegirá a 15 senadores y el neerlandés a los 25 senadores electos restantes. El segundo grupo de 21 senadores lo conforman los senadores comunitarios, 10 elegidos por el Consejo de la Comunidad Francófona, 10 por el Consejo de la Comunidad Flamenca y 1 por el Consejo de la Comunidad Germanófona. El tercer grupo de 10 senadores lo constituyen los senadores de cooptación, elegidos en número de 6 y 4 por los senadores neerlandeses y francófonos de los dos grupos anteriormente analizados según el principio de representación proporcional. Y el último grupo está constituido por los senadores de derecho propio, los hijos del monarca. 
crucial a la hora de aprobar legislación fundamental y de proteger los intereses de las entidades federadas.

Y por último, se concretó una amplia autonomía a favor de las entidades federadas en tres ámbitos cruciales: autonomía en el ámbito de las Relaciones Internacionales en el marco de sus competencias exclusivas con la única limitación de respetar la coherencia de la política exterior definida por la federación ante el especial papel internacional que juega Bélgica en el proceso de integración europea; autonomía constituyente, por la cual las regiones y comunidades pueden modificar la organización de sus instituciones sobre determinados puntos o aspectos esenciales relativos a la composición, elección y funcionamiento de sus consejos y gobiernos respectivos; y autonomía fiscal de comunidades y regiones atemperado por los principios de responsabilidad política y de solidaridad interregional que garantice una convergencia en los niveles de bienestar de los ciudadanos belgas.

\section{FEDERALISMO CONSOCIACIONAL PROTECTOR DE LAS MINORÍAS}

Este proceso de federalización de Bélgica había que completarlo con mecanismos consociacionales de protección de las minorías lingüísticas, francófona y neerlandesa, que coexistían en un mismo territorio. Es por ello, que las sucesivas reformas constitucionales han ido perfilando todo un arsenal de salvaguardas, un complejo sistema de frenos y contrapesos para el sistema institucional federal, de cara a proteger a la minoría poblacional francófona a nivel nacional (40\% de la población nacional), e igualmente para la región de Bruselas-capital para proteger, esta vez, a la minoría neerlandesa (15\% de la población regional). La capital del reino ha sufrido un gradual proceso de afrancesamiento a lo largo de los siglos ante la formidable expansión de la administración central.

Estos mecanismos de protección de las minorías lingüísticas en las instituciones políticas federales y regionales añaden dosis adicionales de extrema complejidad al sistema político belga, ante las nefastas consecuencias polarizantes que podría conllevar el principio de la mayoría ${ }^{30}$. En lo que respecta al nivel federal, junto a la representación de las comunidades, y en menor medida, de las regiones en el Senado belga, la protección de la minoría francófona se materializa a través de varios mecanismos y fórmulas ${ }^{31}$. La Constitución prevé en su artículo 43 que ambas cámaras del parlamento federal se dividan internamente en dos grupos lingüísticos, uno de habla francesa y

30 A.P. FROGNIER, "The mixed nature of Belgian Cabinets: between mayority rule and consociationalism", European Journal of Political Research, 1988, vol. 16, pág. 207.

31 Para un análisis teórico de los instrumentos consociacionales introducidos en Bélgica, véase T. KNAPPSKOG, "Consociationalism: Theoretical Development Illustrated by the Case of Belgium", Res Publica, 2001/4, vol. XLIII, págs. 529-550. 
otro de habla neerlandesa ${ }^{32}$, los cuales tendrán el derecho de accionar el procedimiento de sirena de alarma — sonnette d'alarme- Para evitar la aprobación de piezas legislativas, iniciadas en cualquiera de las cámaras del parlamento federal, de una naturaleza tal que afectasen gravemente a los intereses políticos, económicos o sociales de alguna comunidad lingüística, en especial de la francófona por estar en minoría en dichas cámaras, o a las relaciones entre las dos principales comunidades federales se establece este mecanismo regulado en el artículo 54 de la Constitución que puede ser accionado por cualquiera de estos grupos. Esta moción motivada y firmada por al menos 3/4 de los miembros de un grupo lingüístico resulta en la suspensión del procedimiento parlamentario ordinario de dicha pieza, que será remitida al gabinete federal, con igual número de ministros francófonos que neerlandeses, que en un plazo de 30 días intentará encontrar una solución de consenso que solucione el conflicto. Junto a este procedimiento de sirena de alarma, la Constitución belga prevé las leyes federales de mayoría especial definidas como actos o decisiones del parlamento federal —básicamente las reformas de Estado y actos o decisiones que afecten a la aplicación de los principios constitucionales sobre la estructura del Estado y de la organización institucional - que para ser aprobadas deben pasar por mayoría en cada uno de los grupos lingüísticos existentes en cada cámara federal, siempre y cuando la mayoría de los miembros de cada grupo estén presentes, y los votos totales a favor en cada cámara alcancen una mayoría cualificada de $2 / 3$. Su objetivo es evitar que estas propuestas de reforma de Estado pudieran ser aprobadas en contra de la voluntad o intereses de alguna de las dos comunidades principales. Junto a estas medidas anteriores, que van dirigidas a proteger los intereses de la minoría francófona en el legislativo federal, la Constitución inscribe el principio de paridad lingüística a la hora de fijar la composición del gabinete federal ${ }^{33}$, de los principales órganos jurisdiccionales federales, como la Corte de Arbitraje, la Corte de Casación y el Consejo de Estado, así como de la administración federal a partir de un determinado nivel funcionarial. De esta forma, se garantiza que en todos estos órganos federales habrá un mismo número de miembros francófonos que neerlandeses, es decir una representación equitativa de ambas comunidades lingüísticas que sobre-representa a la minoritaria en cada nivel respectivo de gobierno.

Mecanismos de protección, casi idénticos a los analizados previamente en el nivel federal, fueron introducidos a nivel de la Región de Bruselas-

32 Al igual que en el nivel regional de Bruselas-capital, al presentar sus candidaturas los candidatos deben declarar e inscribirse en el grupo lingüístico al cual pertenecerían en caso de salir elegidos. Así, los diputados federales y regionales bruselenses elegidos a partir de listas francófonas constituirán el grupo lingüístico francófono y los diputados federales y regionales elegidos a partir de listas neerlandesas pasarán a formar parte del grupo lingüístico neerlandés.

33 De acuerdo al artículo 99 de la Constitución belga, de los 15 miembros del gabinete federal, 7 serán ministros francófonos y 7 neerlandeses, salvándose de esta paridad lingüística gubernamental, tanto el primer ministro, cuando el número de miembros del gabinete sea impar, como los secretarios de estado al no contar éstos con asiento en el gabinete. 
capital para proteger, esta vez, a la minoría neerlandesa. Entre estas salvaguardas trazadas desde la reforma de Estado de 1970 resaltan la obligación de conformar en el Consejo regional dos grupos lingüísticos, el "procedimiento de sirena de alarma", la paridad lingüística en la composición del gobierno regional ${ }^{34}$, y el equilibrio entre francófonos y flamencos en los puestos de la administración regional de Bruselas.

Todos estos mecanismos y salvaguardas permiten que exista un ejercicio o gestión conjunta del poder político, tanto a nivel federal, como comunitario y regional, que fortalece las estructuras políticas del Estado y permite la coexistencia pacífica de la diversidad etnocultural existente en la sociedad.

\section{BÉLGICA: ¿UN FEDERALISMO DE CONFRONTACIÓN A LA DERIVA?}

Del análisis de estos aspectos del sistema político belga, como su extrema complejidad, la incongruencia o asimetría federal promovida por cada comunidad y región, la polarización extrema de la cuestión lingüística en todos los aspectos de la vida social, económica, cultural y política del país, y su carácter centrífugo, se podría sugerir que este esquema federal tiene los días contados. Este Estado, que nació de la secesión del reino de los Países Bajos a partir de un proceso de independencia en 1830 que no presentó todos los rasgos particulares de un proceso de afirmación o de formación nacional, podría dar la impresión de que está amenazado por el peligro de la secesión. El tradicional conflicto de reivindicaciones lingüísticas deja paso a uno centrado en reivindicaciones institucionales, donde tanto la escisión como el rattachismo dejan de ser cuestiones tabúes para ambas comunidades $^{35}$. Igualmente, la federalización del Estado no ha suscitado grandes emociones entre los ciudadanos sino que ha aparecido como un auténtico show político de las elites. La complejidad introducida por las sucesivas reformas, la incomprensible jerga de la técnica jurídica y el descrédito del sistema de partidos y del poder judicial y policial por los escándalos Agusta, Dassault o Dutroux, ha superado la comprensión de los ciudadanos. Se impone un déficit democrático toda vez que los ciudadanos ya no tienen una visión clara

34 No se ajustarán a esta regla de la paridad lingüística numérica de miembros francófonos y neerlandeses aplicada a este gabinete regional, constituido por cinco miembros, dos ministros francófonos y dos flamencos, el ministro-presidente y los tres secretarios de estado regionales, de los cuales, al menos uno tiene que ser flamenco, lo que permite reflejar de una forma más acertada la composición de la sociedad bruselense.

35 L. ONKELINX, "Perspectives, les refus de la disparition du pouvoir fédéral ", Problèmes Politiques et Sociaux, n. ${ }^{\circ}$ 795, en J-C BOYER, Belgique : l'Etat Fédéral, une étape?, diciembre de 1997, pág. 62. Conscientes de la escasa viabilidad como Estado de Valonia por su talla demográfica y sus dificultades económicas, existe un pequeño movimiento republicano rattachiste "Mouvement pour le retour de la Wallonie à la France" partidario de la adhesión de Valonia a Francia, que es especialmente fuerte en Lieja. 
de las estructuras institucionales y del proceso decisorio. Este complejo entramado ha acrecentado la indiferencia y apatía de la ciudadanía ${ }^{36}$.

La propia división/escisión de los tradicionales partidos políticos belgas en familias lingüísticas, que hace que no exista partido alguno de ámbito nacional o federal, era considerado como un elemento que dificultaría extraordinariamente, no sólo una política central efectiva, sino sobre todo un compromiso equilibrado definitivo sobre la organización del Estado por los requisitos de autonomía de las unidades federadas que ellos representan a toda costa ${ }^{37}$. Pero esta segmentación lingüística no se ha limitado a los partidos. Se ha extendido al resto de organizaciones sociales, asociaciones culturales, medios de comunicación, sindicatos, organizaciones patronales, e incluso a las órdenes religiosas. Bélgica es una sociedad donde todos se sienten pertenecientes a una minoría, y además frustrados, ya sea por agravios pasados o presentes ${ }^{38}$.

Es como si la historia interminable de ocupaciones extranjeras - española, austriaca, francesa y neerlandesa- de Bélgica hubiera destruido todo rastro de sentimiento nacional ${ }^{39}$. A pesar del sistema institucional y de las reglas políticas introducidas, la confrontación entre ambas comunidades y el conflicto lingüístico acapara todo el campo político belga ${ }^{40}$. Numerosas cuestiones adquieren una indudable significación etno-regional. Las exigencias de regionalización de la seguridad social y de mayor autonomía fiscal para las entidades federadas, la amnistía a los colaboradores de los nazis, el tren de alta velocidad, el presupuesto de la Agencia Europea Espacial, la venta de armas a Oriente Medio, la muerte del rey Balduino en julio de 1993, la ley antitabaco del 10 de diciembre de 1997, o incluso la política exterior de Bélgica en la zona de los grandes lagos de África Central, y más concretamente la comisión de investigación sobre el genocidio en Ruanda y el cambio de régimen en el Congo-Zaire en mayo de 1997, son planteadas como conflictos entre ambas comunidades, como juegos de suma cero de dimensión comunitaria ${ }^{41}$.

Estas sucesivas reformas constitucionales, lejos de calmar la confrontación entre las comunidades, han reforzado las aspiraciones y reivindicaciones de las mismas y surgen nuevos y continuos puntos de fricción en el proceso de federalización. La federalización queda como una cuestión abierta e inacabada, aunque la confrontación entre ambas comunidades ya no se centre en

36 J., NICO ET M. VAN DEN WIJNGAERT, "Un Bilan ", Problèmes Politiques et Sociaux, n. ${ }^{\circ}$ 795, en J-C. BOYER, Belgique : l'Etat Fédéral, une étape?, diciembre de 1997, pág. 45.

37 K. DESCHOUWER, "The Unintended consequences of Consociational Federalism: the case of Belgium", en I. O'FLYNN Y D. RUSSELL, Power Sharing, New challenges for divided societies, Pluto Press, Londres, 2005, pág. 103.

38 D. REA, op. cit., pág. 213.

39 J. BEAUFAYS, op. cit., pág. 233.

40 P. DELWIT, J-M.L DE WAELE. P. MAGNETTE (Dir.), Gouverner la Belgique, Clivages et Compromis dans une Société Complexe, Presses Universitaires de France, Vendôme, 1999, pág. 64.

41 S. FIERS, M. DEWEERDT, "Belgian Politics in 1998", Res Publica, Vol. XLI, 1999, pág. 277 ; X. DE MABILLE, "Etat et nations, la formation de l'Etat Belge ", Problèmes Politiques et Sociaux, n. ${ }^{\circ}$ 795, en J-C. BOYER, Belgique: l'Etat Fédéral, une étape?, diciembre de 1997, pág. 4. 
cuestiones lingüísticas o culturales sino en cuestiones económicas, sociales, y sobre todo institucionales. El debate actual sobre las futuras reformas institucionales sale a escena el 29 de febrero de 1996, cuando Luc Van del Branden, ministro-presidente de Flandes presentó ante el parlamento flamenco una propuesta sobre la futura estructura y organización política federal de Bélgica, que fue confirmada y desarrollada el 11 de julio de 1997, con ocasión de la fiesta de la Comunidad Flamenca, por el presidente del parlamento flamenco, el socialista Norbert De Batselier. En sus respectivas intervenciones se delinearon las grandes orientaciones de una nueva reforma de Estado. Por un lado, se incluía una estructura confederal compuesta por dos estados federados -Flandes y el Estado federado francófono- y dos territorios federados - la Región de Bruselas-capital y la Comunidad Germanófona-, y por otro, se proponía un nuevo reparto de competencias entre los niveles de gobierno que incluiría la regionalización de la Seguridad Social y una mayor autonomía fiscal para las entidades federadas. Para muchos esta iniciativa confederal puede ser el inicio de cómo este federalismo de cooperación se transformaría en un federalismo de enfrentamiento y separación ${ }^{42}$. Los nueve meses de ausencia de gobierno federal en Bélgica tras las elecciones de junio de 2007 pueden ser la consecución de una crónica anunciada de cómo las sucesivas crisis políticas y la excesiva efervescencia política del debate público de los últimos años han erosionado progresivamente la confianza mutua entre los socios y ha exacerbado los conflictos comunitarios paralizando el gobierno del Estado central ${ }^{43}$.

Siendo cada esquema político en sí mismo un modelo sui generis, donde las estructuras políticas no pueden ser disociadas de sus propios factores geográficos, culturales, económicos, históricos e ideológicos, sería importante resaltar un aspecto crucial de la experiencia política belga de los últimos años. La descentralización del poder político en Bélgica ha promovido nuevos patrones de comportamiento de las élites políticas involucradas en el proceso. Esta constelación de herramientas consociacionales ha creado una nueva cultura política basada en el compromiso pacífico y en un amplio consenso entre los diferentes grupos etno-nacionales ${ }^{44}$. Salvo algunos episodios aislados de violencia provocados a raíz de la fijación de las fronteras lingüísticas y de los titubeos en las concesiones del tratamiento lingüístico preferencial a las comunas de facilidad, hay que felicitar la vía pacífica que Bélgica ha tomado para encontrar una solución al conflicto existente en esta sociedad

42 P. DELWIT, J-M. DE WAELE, P. MAGNETTE (Dir.), Gouverner la Belgique, Clivages et Compromis dans une Société Complexe, Presses Universitaires de France, Vendôme, 1999, pág. 69; P. BUSQUIN, "Les changements en Belgique de 1980 à 2000. La vue d'un président de parti ", Res Publica Belgique 1980-2000, 2001, pág. 90. De hecho, estos anuncios a favor de esquemas confederales fomentaron un clima de desconfianza que hizo que tras las elecciones de 1999 los partidos políticos francófonos se constituyeran en un bloque unánime contra las nuevas reformas institucionales.

43 P. DE BRUYCKER, M. LEROY, J. SOHIER, P. VANDERNACHT, P. VANDERNOOT, op. cit., pág. 195.

44 T.J. MAARTEN, Op. cit., pág. 41. 
polarizada por la cuestión lingüística ${ }^{45}$. Bélgica ha celebrado la aparición de unas pautas de comportamiento político que han sido posibles gracias justamente a los mecanismos de cooperación y, de forma subyacente, al principio del derecho público alemán Bundestreue por el cual se requiere que la autoridad federal o las entidades federadas tengan en cuenta los intereses de la otra al ejercer sus competencias propias. El factor de cohesión ha primado hasta ahora sobre el de autonomía. La experiencia belga ha sido, y es, una forma única e irrepetible para conciliar la unidad con la diversidad. A pesar de las nuevas exigencias puestas sobre la mesa por los flamencos, el funcionamiento del sistema político belga ha dependido siempre de un equilibrio clásico. Y a pesar de los conflictos actuales el compromiso belga siempre ha superado estos desafíos.

De cualquier forma, es importante resaltar cómo, a pesar de esta nueva cultura política basada en el consenso y en el compromiso, en este proceso federalizador tienden a imponerse los elementos centrífugos sobre los centrípetos. En un marco de segmentación y polarización imparable a lo largo de las líneas lingüísticas, Flandes y Valonia surgen como pueblos o sociedades crecientemente diferenciadas con visiones divergentes sobre el futuro del Estado $^{46}$. Y para agravar la situación, se han frenado los flujos migratorios entre el norte y sur del país y con ello las posibilidades para la interacción y comunicación entre dichas sociedades.

Gestionar y mitigar conflictos asociados a la heterogeneidad etnocultural de las sociedades plurales y segmentadas no sólo exige complejas planificaciones constitucionales, normas políticas y esquemas institucionales de acomodación interétnica que reduzcan la bifurcación, fomenten la fluidez multipolar y refuercen los acuerdos de cooperación y los canales de comunicación entre grupos. Es necesario acompasar estos mecanismos institucionales de ingeniería política-constitucional de poder compartido "top-down" con aproximaciones de sociedad civil "bottom-up" que ayuden a eliminar la polarización y división comunal y, de paso, desmitificar los prejuicios, estereotipos, los muros sectarios y comunitarios, las mentalidades de asedio y las rígidas fron-

45 Las crisis de Fourons y de Mouscron-Comines se iniciaron a raíz de la implementación de la ley de la frontera lingüística de julio de 1962. Mientras la comuna francófona de Fourons, ubicada inicialmente en Valonia, fue anexionada contra su voluntad a la provincia flamenca de Limburgo, la comuna neerlandófona de Mouscron-Comines, ubicada inicialmente en Flandes, fue anexionada a la provincia Valona de Hainaut. La concesión de facilidades lingüísticas a sus habitantes no impidió que las rivalidades entre ambas comunidades creciera con el paso del tiempo. En la comuna de Fourons la situación se agravó cuando el movimiento "Acción Fouronnaise", dirigido por el que sería elegido Bourgmestre, José Happart, defendió su vuelta a Lieja, lo que llevó a los militantes del grupo VMO — Vlaamse Militanten Orde - (Milicia Privada Flamenca) a ametrallar el ayuntamiento de Fourons en julio de 1983.

46 W. DEWATCHER, "La menace de l'Intégration européenne ", Problèmes Politiques et Sociaux, n. ${ }^{795}$, en J-C. BOYER, Belgique : l'Etat Fédéral, une étape?, diciembre de 1997, pág. 67 ; M. ROESSINGH, Ethnonationalism and Political Systems in Europe: A State of Tension, Amsterdam University Press, Amsterdam, 1996, pág. 189; J. FONTAINE, "Sur la nation belge", Le Débat, n. ${ }^{\circ}$ 97, noviembre-diciembre 1997, pág. 186. 
teras de identidad entre nosotros y ellos que hacen que las gentes sean rehenes de posiciones recalcitrantes e inmovilistas " ${ }^{47}$. Con esta aproximación de sociedad civil, con esta estrategia de intercambio humano se crearán los espacios de diálogo y conocimiento mutuo y los oleoductos de contactos intergrupales necesarios que incidan en la dimensión estructural y psicocultural de todo conflicto etnonacional y ofrecerá una vía de escape para el actual proceso de suma cero de negociación entre elites que vive Bélgica.

Para terminar, de cara a contrarrestar esta deriva aislacionista y diferenciadora, es necesario un enorme esfuerzo por todos de pedagogía política no partidista ante la complejidad inherente de este enriquecimiento de la democracia belga. Aunque "no es seguro que el Estado belga, en su forma actual, sobreviva durante mucho tiempo" ${ }^{48}$, merece la pena apostar por este modelo original de contrato de vida en común diseñado a partir de un proceso permanente de negociación.

TiтLE: Federalism and democracy consociacional in the Belgian politics.

AвSTRACT: Over the past forty years the unitary Belgian state has federalized its institutions through successive state reforms, as a response to internal diversity, eventually leading to a constitutional revision formalizing its federal character in 1993. Among the main characteristics of the Belgian federal system is asymmetry, as this country displays the unique feature of possessing two superimposed sets of sub-national institutions: the three regions (Flanders, Wallonia and Brussels), as a demand made by the Francophone population, and the three communities (Flemish, French and German-speaking communities) - a demand made by the Flemish population-. But this bipolar, complex, centrifugal federalism coexist with advanced consociational features of the Belgian polity.

Resumen: A lo largo de los últimos cuarenta años el estado unitario y centralizado belga ba federalizado sus instituciones y estructuras a raiz de las sucesivas reformas de Estado llevadas a cabo, en respuesta a la diversidad etno-cultural interna. Entre las prinicipales características del esquema federal de Bélgica, formalizado con la reforma constitucional de 1993, destacan su carácter asimétrico y bipolar, en tanto en cuanto combina y superpone simultáneamente dos tipos de entidades subnacionales, las regiones (Flandes, Valonia y la Bruselas-capital), defendidas por los francófonos, y las comunidades (flamenca, francófona y germanofrancófona), promovidas por los flamencos. Pero el carácter bipolar, complejo, centrífugo y asimétrico del federalismo bela coexiste con avanzados rasgos consociacionales.

KEY WORDS: Federalism. Consociationalism. Asymmetric and bipolar federalism. Ethnonattionalism. Linguistic minorities. State reforms. Diversity.

Palabras clave: Federalismo. Consociacionalismo. Asimetría. Bipolaridad. Etno-nacionalismo. Minorías lingüísticas. Reformas de Estado. Diversidad.

47 B. REILLY, A. REYNOLDS, "Electoral Systems and Conflict in Divided Societies", M. A. ROESSINGH, Ethnonationalism and Political Systems in Europe, A State of Tension, Amsterdam University, Amsterdam, 1996, págs. 422 y ss; E. MANSFIELD, J. SNYDER, "Democratization and War", Foreign Affairs, n. ${ }^{\circ}$ 74, 1995, págs. 79-97; L. HARBOM y P. WALLENSTEEN, "Armed Conflict and its International Dimensions, 1946-2004", Journal of Peace Research, Vol.42, n. 5, 2005, págs. 623-635.

48 A. BAECQUEANTOINE, Une Historie de la Democracie en Europe, Le Monde Editions, París, 1991, pág. 224. 